\title{
Interleukin-18 Induces Angiogenic Factors in Rheumatoid Arthritis Synovial Tissue Fibroblasts via Distinct Signaling Pathways
}

\author{
Mohammad A. Amin, ${ }^{1}$ Pamela J. Mansfield, ${ }^{1}$ Angela Pakozdi, ${ }^{1}$ Phillip L. Campbell, ${ }^{1}$ \\ Salahuddin Ahmed, ${ }^{1}$ Rita J. Martinez, ${ }^{1}$ and Alisa E. Koch ${ }^{2}$
}

Objective. Interleukin-18 (IL-18) is a proinflammatory cytokine implicated in the pathogenesis of rheumatoid arthritis (RA). This study was undertaken to examine the role of IL-18 in up-regulating secretion of the angiogenic factors stromal cell-derived factor $1 \alpha$ (SDF-1 $\alpha) / C X C L 12$, monocyte chemoattractant protein 1 (MCP-1)/CCL2, and vascular endothelial growth factor (VEGF) in RA synovial tissue (ST) fibroblasts, and the underlying signaling mechanisms involved.

Methods. We used enzyme-linked immunosorbent assays, Western blotting, and chemical inhibitors/ antisense oligodeoxynucleotides to signaling intermediates to assess the role of IL-18.

Results. IL-18 significantly enhanced the production of SDF-1 $\alpha /$ CXCL12, MCP-1/CCL2, and VEGF in RA ST fibroblasts, in a time- and concentrationdependent manner. IL-18-induced SDF-1 $\alpha /$ CXCL12 up-regulation was dependent on JNK, p38 MAPK, phosphatidylinositol 3-kinase (PI3K), and NFKB. While IL18-induced production of SDF-1 $\alpha /$ CXCL12 was also dependent on protein kinase $\mathrm{C} \delta$ (PKC $\delta$ ), production of MCP-1/CCL2 was dependent on PKC $\alpha$, not PKC $\delta$.

Dr. Amin's work was supported by the NIH (grant R03-AR052482-01A1). Dr. Koch's work was supported by the Veterans Administration Research Services, by the NIH (grants AI-40987, HL-58695, and AR-48267), by a Frederick G. L. Huetwell and William D. Robinson Professorship at the University of Michigan, and by a postdoctoral fellowship grant from the American Heart Association.

${ }^{1}$ Mohammad A. Amin, MD, Pamela J. Mansfield, MS, Angela Pakozdi, MD, Phillip L. Campbell, BS, Salahuddin Ahmed, PhD, Rita J. Martinez, BS: University of Michigan Health System, Ann Arbor; ${ }^{2}$ Alisa E. Koch, MD: Department of Veterans Affairs and University of Michigan Health System, Ann Arbor.

Address correspondence and reprint requests to Mohammad A. Amin, MD, Department of Internal Medicine/Division of Rheumatology, University of Michigan Medical School, 4428 BSRB, 109 Zina Pitcher Drive, Ann Arbor, MI 48109-2200. E-mail: maamin@med. umich.edu.

Submitted for publication July 27, 2006; accepted in revised form March 7, 2007.
Additionally, RA ST fibroblast IL-18-induced MCP-1/ CCL2 production was mediated by JNK, PI3K, and NF $\kappa$ B. In contrast, IL-18 did not induce secretion of RA ST fibroblast MCP-1/CCL2 or VEGF via p38 MAPK. IL-18-induced RA ST fibroblast production of VEGF was mediated mainly by JNK-2, PKC $\alpha$, and NF $\kappa \mathrm{B}$. IL-18 induced phosphorylation of JNK, PKC $\delta$, p38 MAPK, and activating transcription factor 2 (ATF-2) in RA ST fibroblasts in a time-dependent manner, with JNK-2 being upstream of PKC $\delta$, ATF-2, and NFкB.

Conclusion. These data support the notion that IL-18 has a unique role in inducing the secretion of angiogenic SDF-1 $\alpha /$ CXCL12, MCP-1/CCL2, and VEGF in RA ST fibroblasts, via distinct signaling intermediates.

Interleukin-18 (IL-18) is a proinflammatory cytokine, structurally related to IL- $1 \beta$ and originally described as interferon- $\gamma$-inducing factor (1). IL-18 induces tumor necrosis factor $\alpha(\mathrm{TNF} \alpha)$, IL- $1 \beta$, granulocyte-macrophage colony-stimulating factor, nitric oxide, and chemokine production by monocytes and $\mathrm{T}$ lymphocytes $(2,3)$. Significantly elevated levels of IL-18 are present in the synovial fluid, synovial tissue (ST), and sera of patients with rheumatoid arthritis (RA) compared with patients with osteoarthritis (OA) (4). Studies with murine models of RA show that IL-18 plays a key role in the pathogenesis of arthritis, since the administration of IL-18 to mice with collagen-induced arthritis (CIA) increases the severity of arthritis, and its blockade suppresses joint swelling in the murine streptococcal cell wall-induced arthritis model $(5,6)$ and ameliorates arthritis in murine CIA (4).

Stromal cell-derived factor $1 \alpha(\mathrm{SDF}-1 \alpha) /$ CXCL12 is a CXC chemokine produced by bone marrow stromal cells (7). SDF-1 $\alpha /$ CXCL12 plays an important role in the pathogenesis of RA, in that it mediates homing of leukocytes to RA ST and causes the release of 
matrix metalloproteinase 3 (MMP-3) by chondrocytes $(8,9)$. SDF- $1 \alpha /$ CXCL12 increases the migration and survival of $\mathrm{B}$ and $\mathrm{T}$ cells in vitro, and exogenous SDF$1 \alpha /$ CXCL12 increases monocyte migration in a dosedependent manner in a SCID/RA ST chimera model $(9,10)$. Moreover, an antagonist of CXCR4 (a receptor for SDF-1 $\alpha /$ CXCL12) ameliorates arthritis in murine CIA (11). SDF- $1 \alpha /$ CXCL12 is also a potent angiogenic factor and has been demonstrated to induce angiogenesis in several in vitro and in vivo models $(12,13)$. Interestingly, CXCR4-null mice exhibit gross defects in vascularization, suggesting a critical role of SDF-1 $\alpha /$ CXCL12 in normal vascular development (14).

Cytokines such as TNF $\alpha$, IL- $1 \beta$, and monocyte chemoattractant protein 1 (MCP-1)/CCL2 play an important role in the pathogenesis of RA by directing leukocyte trafficking $(15,16)$. Levels of the CC chemokine MCP-1/CCL2 are elevated in RA synovial fluid compared with OA synovial fluid (15). Monocyte recruitment and cytokine expression are impaired in MCP1/CCL2-deficient mice, providing evidence of the role of MCP-1/CCL2 in RA pathogenesis (17). MCP-1/CCL2 attracts memory $\mathrm{T}$ lymphocytes and natural killer cells, which have a major function in RA (18). MCP-1/CCL2 mediates angiogenesis in vitro and in vivo via vascular endothelial growth factor (VEGF) (19). Anti-rat MCP1/CCL2 neutralizing antibody has been found to significantly reduce the number of macrophages and $\mathrm{T}$ cells in the joint and to reduce ankle swelling in rat adjuvantinduced arthritis (20).

VEGF is a prototypic angiogenic factor which induces endothelial cell proliferation, angiogenesis, and capillary permeability $(21,22)$. It is secreted by a variety of cell types such as fibroblasts, macrophages, endothelial cells, lymphocytes, and osteoblasts (22). Significantly higher levels of VEGF are present in RA synovial fluid compared with OA synovial fluid (23). Treatment with soluble VEGF receptor 1 attenuates arthritis severity in murine CIA (24).

The role of IL-18 in the pathogenesis of RA remains incompletely understood. Our group has previously shown that IL-18 up-regulates CXC chemokines such as IL-8/CXCL8, growth-regulated oncogene $\alpha$ $(\mathrm{GRO} \alpha) / \mathrm{CXCL} 1$, and epithelial neutrophil-activating peptide 78 (ENA-78)/CXCL5 in RA ST fibroblasts $(25,26)$. In this study, we demonstrated that IL-18 increases the production of SDF- $1 \alpha /$ CXCL12, MCP-1/ CCL2, and VEGF via overlapping but distinct signaling pathways. We report the role of JNK, phosphatidylinositol 3-kinase (PI3K), p38 MAPK, activating transcription factor 2 (ATF-2), and $\mathrm{NF} \kappa \mathrm{B}$ in up-regulating these angiogenic factors. In some instances, we confirmed our results with the use of sense and antisense oligodeoxynucleotides (ODNs) of signaling intermediates. IL-18 induced RA ST fibroblast phosphorylation of JNK-2, $\mathrm{ATF}-2$, protein kinase $\mathrm{C} \delta(\mathrm{PKC} \delta)$, and $\mathrm{NF} \kappa \mathrm{B}$, in a time-dependent manner. We describe a novel pathway for IL-18 in the activation of PKC $\delta$ and ATF-2. Our results suggest that IL-18 and its signaling pathways may be potential targets in inflammatory, angiogenic diseases such as RA.

\section{MATERIALS AND METHODS}

Reagents. Recombinant human IL-18 was purchased from R\&D Systems (Minneapolis, MN). Signaling inhibitors used were PD98059 (an ERK-1/2 inhibitor), LY294002 (a PI3K inhibitor), PP2 (an Src inhibitor), pyrrolidine dithiocarbamate (PDTC) (an NF $\kappa$ B inhibitor), Rottlerin (an inhibitor of PKC $\delta$ ), RO-318425 (a relatively specific inhibitor of $\mathrm{PKC} \alpha_{\mathrm{I}} /$ $\beta_{\text {II }}$ ), SP600125 (a JNK-1/2 inhibitor), SB203580 (a p38 MAPK inhibitor), and AG-490 (a JAK-2 inhibitor). All inhibitors were purchased from Calbiochem (San Diego, CA). Cells were pretreated for 1 hour with $10 \mu M$ of each inhibitor before stimulation with IL-18 $(25 \mathrm{n} M)$, as described previously (2527). TNF $\alpha$ (1.15 nM; Upjohn, Kalamazoo, MI) and phosphate buffered saline (PBS) were used as positive and negative controls, respectively.

Preparation of RA ST fibroblast-conditioned media. Fresh RA ST was minced and digested in a solution of Dispase, collagenase, and DNase, as described previously (28). The ST fibroblasts were used at passage 3 or later, at which time they are a homogeneous population. ST fibroblasts $\left(1.5 \times 10^{5}\right.$ cells/well) were plated for 24 hours in 6-well plates in RPMI 1640-10\% fetal bovine serum (FBS; Gibco BRL, Grand Island, NY). FBS was then reduced to $5 \%$ for 24 hours, and subsequently to $0 \%$ for 24 hours; FBS was tapered gradually because we have noted in the past when working with RA ST fibroblasts that the morphologic features of these cells change, and they become apoptotic, if medium with 10\% FBS is immediately switched to $0 \%$ FBS. We starve RA ST fibroblasts for 24 hours to remove the effect of FBS, since there are many factors in serum that can stimulate these cells, leading to false-positive results $(25,26,29)$. RA ST fibroblasts were stimulated for 24 hours with IL-18 $(25 \mathrm{n} M)$. For inhibitor studies, cells were treated with signaling inhibitors $(10 \mu M)$ for 1 hour before stimulation with IL-18; RA ST fibroblasts were stimulated with IL-18 at various concentrations, and supernatants harvested after various lengths of time. DMSO was used as a control for inhibitors. Conditioned medium was collected and stored at $-80^{\circ} \mathrm{C}$ until used to detect cytokines by commercially available enzyme-linked immunosorbent assays (ELISAs; R\&D Systems). The sensitivity of these assays ranged from 5 $\mathrm{pg} / \mathrm{ml}$ to $18 \mathrm{pg} / \mathrm{ml}$. All specimens were obtained with institutional review board approval in compliance with the Helsinki Declaration.

Transfection of RA ST fibroblasts with sense and antisense ODNs. RA ST fibroblasts $\left(1.5 \times 10^{5} /\right.$ well $)$ were plated on 6-well plates and the medium was switched to serum free to minimize the effects of serum as described above. When 
fibroblasts were $70 \%$ confluent, they were transfected for 24 hours with sense and antisense ODNs $(2-5 \mu \mathrm{g})$ directed against JNK, $\mathrm{PKC} \alpha, \mathrm{PKC} \beta, \mathrm{NF} \kappa \mathrm{B}$, and $\mathrm{PKC} \delta$, using TransIT-LT1 reagent according to the instructions of the manufacturer (Mirus, Madison, WI). Sense and antisense ODN sequences of signaling intermediates used were as follows: $\mathrm{PKC} \alpha$ sense TCGGGGGGGACCATG, antisense CATGGTCCCCCCCGA; PKC $\beta$ sense GCTGACCCGGCTGCG, antisense CGCAGCCGGGTCAGC; PKC $\delta$ sense CGAGTAGTTACAGCGG, antisense ACGGTGCCATGATGGA; JNK-1 sense GCTCGGTGGAAATGGATCAG, antisense CTCATGATGGCAAGCAATTA; JNK-2 sense GCTAAGCGGTCAAGGTTGAG, antisense GCTCAGTGGACATGGATGAG; p65 NF $\kappa$ B sense GCCATGGACGAACTGTTCCCC, antisense GGGGAACAG TTCGTCCATGGC. We also transfected RA ST fibroblasts using dominant-negative mutants of p38 MAPK (30). After transfection, RA ST fibroblasts were stimulated for 24 hours with IL-18 $(25 \mathrm{n} M)$, and conditioned medium was collected.

IL-18-induced nuclear translocation of p65 NFкB. To study the effect of IL-18 on NF $\kappa \mathrm{B}$ activation, RA ST fibroblasts were treated for 30 minutes with IL-18 (25 $\mathrm{n} M)$. Cytoplasmic and nuclear fractions were prepared as previously described (29). Cells were washed twice with ice-cold PBS, collected, and centrifuged at $1,500 \mathrm{~g}$ for 5 minutes at $4^{\circ} \mathrm{C}$. The pellet obtained was suspended in $400 \mu \mathrm{l}$ of buffer as previously described (29). To each sample, cold 10\% Nonidet P40 (25 $\mu \mathrm{l})$ was added, the sample was vortexed, and centrifuged at $14,000 \mathrm{~g}$ for 30 seconds. Supernatant (cytoplasmic fraction) was collected, and the nuclear pellet obtained was suspended in 50 $\mu l$ of buffer containing $20 \mathrm{~m} M$ HEPES ( $\mathrm{pH}$ 7.9), $0.4 M \mathrm{NaCl}, 1$ $\mathrm{m} M$ EDTA, $1 \mathrm{~m} M$ EGTA, $1 \mathrm{~m} M$ dithiothreitol, and $1 \mathrm{~m} M$ phenylmethylsulfonyl fluoride, and rocked for 45 minutes at $4^{\circ} \mathrm{C}$. Samples were centrifuged at $14,000 \mathrm{~g}$ for 15 minutes at $4^{\circ} \mathrm{C}$. The supernatant (nuclear fraction) was collected, and nuclear cell lysate $(15 \mu \mathrm{g})$ was used to detect p $65 \mathrm{NF} \kappa \mathrm{B}$ by Western blotting.

Cell lysis and Western blotting. RA ST fibroblasts were incubated in 6-well plates in serum-free medium overnight, before stimulation with IL-18 for various amounts of time to examine the up-regulation of signaling molecules. At the end of each period, cells were lysed with $175 \mu$ l ice-cold lysis buffer $(20 \mathrm{~m} M$ Tris $\mathrm{HCl}$ [pH 7.5], $150 \mathrm{~m} M \mathrm{NaCl}, 1 \mathrm{~m} M$ EDTA, $1 \mathrm{~m} M$ EGTA, 1\% Triton X-100, $2.5 \mathrm{~m} M$ sodium pyrophosphate, $1 \mathrm{~m} M \beta$-glycerophosphate, $1 \mathrm{~m} M \mathrm{Na}_{3} \mathrm{VO}_{4}, 1$ $\mu \mathrm{g} / \mathrm{ml}$ leupeptin) supplemented with Complete Protease Inhibitor Cocktail Tablets (Roche, Indianapolis, IN). The protein concentration in each sample was determined using bicinchoninic acid protein assay kits (Pierce, Rockford, IL).

Cell lysates in Laemmli sample buffer were boiled for 5 minutes, and samples containing equal amounts of protein (15 $\mu \mathrm{g}$ total protein) were subjected to sodium dodecyl sulfate$10 \%$ polyacrylamide gel electrophoresis followed by Western blot analysis (26). Membranes were probed with specific rabbit polyclonal antibodies to phosphorylated JNK, p38 MAPK, PKC $\delta$, p65 NF $\kappa$ B, or ATF-2 (all from Cell Signaling Technology, Beverly, MA). The immunoblots were stripped and reprobed with rabbit anti-human $\beta$-actin (Sigma, St. Louis, MO) to verify equal loading.
Statistical analysis. Statistical significance was determined by Student's $t$ test. $P$ values less than 0.05 were considered significant.

\section{RESULTS}

IL-18-induced SDF-1 $\alpha /$ CXCL12 secretion in RA ST fibroblasts. RA ST fibroblasts were treated for 24 hours with IL-18 to determine up-regulation of SDF-1 $\alpha$ / CXCL12. IL-18-induced SDF-1 $\alpha /$ CXCL12 production was 2 -fold higher than that in unstimulated cells $(P<$ 0.05 ), as determined by ELISA (Figure 1A). The dose of IL-18 was biologically relevant; most of the effects of IL-18 occur with doses in the 1-25 $\mathrm{n} M$ range, and the concentration of IL-18 in RA synovial fluid ranges from 250 to $5,000 \mathrm{pg} / \mathrm{ml}(31)$.

Importance of JNK, PI3K, p38 MAPK, PKC $\delta$, and NF $\kappa$ B in IL-18-induced SDF-1 $\alpha /$ CXCL12 production. To identify the signaling events that are critical for IL-18 induction of SDF-1 $\alpha /$ CXCL12, RA ST fibroblasts were incubated with specific kinase inhibitors $(10 \mu M)$ for 1 hour before stimulation with IL-18 (25 $\mathrm{n} M)$ for 24 hours. We found that the inhibitors of JNK-1/2 (SP600125), PI3K (LY294002), p38 MAPK (SB203580), $\mathrm{PKC} \delta$ (Rottlerin), and $\mathrm{NF} \kappa \mathrm{B}$ (PDTC) significantly $(P<$ $0.05)$ inhibited IL-18-induced SDF-1 $\alpha /$ CXCL12 secretion in RA ST fibroblasts (Figure 1B). This suggests that JNK, PI3K, p38 MAPK, PKC $\delta$, and $\mathrm{NF} \kappa \mathrm{B}$ are important in IL-18-induced up-regulation of SDF- $1 \alpha / \mathrm{CXCL} 12$. These inhibitors reduced SDF- $1 \alpha /$ CXCL12 production to $32-50 \%$ of the levels observed with IL-18 stimulation alone (50-68\% inhibition). In contrast, the inhibitors of JAK-2 (AG-490) and ERK-1/2 (PD98059) did not inhibit SDF-1 $\alpha / \mathrm{CXCL} 12$ production (Figure 1B), indicating that SDF-1 $\alpha /$ CXCL12 secretion by IL-18 was not dependent on these kinases. Similarly, Src and PKC $\alpha_{\mathrm{I}} /$ $\beta_{\text {II }}$ were not important for SDF- $1 \alpha /$ CXCL12 production (data not shown). We did not find toxic effects of chemical inhibitors or decreased viability of fibroblasts with the $10-\mu M$ concentration of inhibitors used $(25,26,29,30,32)$.

Inhibition of IL-18-mediated SDF-1 $\alpha$ /CXCL12 production by $\mathrm{PKC} \delta$ antisense ODN and dominantnegative mutants of $\mathbf{p 3 8}$ MAPK. To confirm the specificity of the signaling pathways involved in SDF-1 $\alpha$ / CXCL12 up-regulation, we transfected RA ST fibroblasts for 24 hours with $\mathrm{PKC} \alpha$ and $\mathrm{PKC} \delta$ sense and antisense ODNs and with p38 MAPK dominantnegative mutants. Cells transfected with $\mathrm{PKC} \delta$ antisense ODN and p38 MAPK dominant-negative mutants produced significantly less SDF- $1 \alpha / \mathrm{CXCL} 12$ compared with 
A
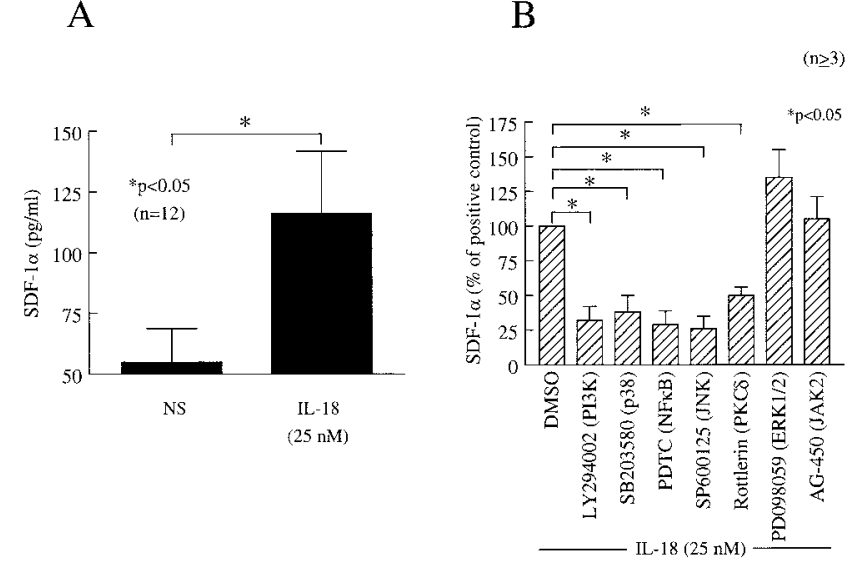

Figure 1. A, Stimulation of stromal cell-derived factor $1 \alpha$ (SDF-1 $\alpha) /$ CXCL12 production in rheumatoid arthritis (RA) synovial tissue (ST) fibroblasts by interleukin-18 (IL-18). Cells were stimulated for 24 hours with IL-18 (25 $\mathrm{nM})$. Conditioned medium was collected, and the quantity of SDF- $1 \alpha /$ CXCL12 released was determined by enzymelined immunosorbent assay. NS $=$ not stimulated. $\mathbf{B}$, Reduction of IL-18-mediated SDF- $1 \alpha /$ CXCL12 production by treatment with inhibitors of phosphatidylinositol 3-kinase (PI3K), p38 MAPK, NF $\kappa \mathrm{B}$, JNK, and protein kinase $\mathrm{C} \delta(\mathrm{PKC} \delta)$. RA ST fibroblasts were treated with signaling inhibitors or DMSO (positive control) for 1 hour before 24-hour stimulation with $25 \mathrm{n} M$ IL-18. PDTC = pyrrolidine dithiocarbamate. C, Significant inhibition of IL-18-induced SDF-1 $\alpha /$ CXCL12 enhancement in RA ST fibroblasts by transfection with $\mathrm{PKC} \delta$ antisense oligodeoxynucleotide (ODN) or dominant-negative mutants of p38 MAPK compared with PKC $\delta$ sense ODN and control for p38 mutant, respectively. PKC $\alpha$ antisense and sense ODNs did not inhibit IL-18-induced SDF- $1 \alpha /$ CXCL12 production. Values are the mean and SEM.

cells transfected with $\mathrm{PKC} \delta$ sense ODN and control used for p38 MAPK mutants (Figure 1C). In contrast, we did not find any difference in the level of IL-18induced SDF- $1 \alpha /$ CXCL12 secretion in fibroblasts transfected with PKC $\alpha$ antisense ODN.

IL-18-induced MCP-1/CCL2 production in RA ST fibroblasts. Our group has previously shown that IL-18 up-regulates production of the CXC chemokines ENA-78/CXCL5, GRO $\alpha /$ CXCL1, and IL-8/CXCL 8 by RA ST fibroblasts (25). In the present study, in order to examine whether IL-18 up-regulates CC chemokine production also, we investigated production of MCP-1/ CCL2. We found that IL-18 induced a significant $(P<$ 0.05 ) increase in MCP-1/CCL2 production in RA ST fibroblasts compared with production in cells not treated with IL-18 (Figure 2A).

Role of JNK-2, PI3K, NF $\kappa B$, and PKC $\alpha$, but not p38 MAPK, in IL-18 mediation of MCP-1/CCL2 production. Inhibitors of JNK- $1 / 2, \mathrm{PI} 3 \mathrm{~K}, \mathrm{NF} \kappa \mathrm{B}$, and $\mathrm{PKC} \alpha_{\mathrm{I}} / \beta_{\mathrm{II}}$ significantly reduced MCP-1/CCL2 production. All 4 inhibitors essentially blocked stimulation of cytokine release, reducing MCP-1/CCL2 levels to those found in unstimulated cells (Figure 2B); this effect was not observed with inhibitors of p38 MAPK and JAK-2. Thus, while IL-18-induced RA ST fibroblast SDF- $1 \alpha /$ CXCL12 production proceeded via p38 MAPK, MCP-1/CCL2 production did not, suggesting that IL-18-induced MCP-1/CCL2 production and IL-18-induced SDF- $1 \alpha /$ CXCL12 production may be mediated via different kinases.

Inhibition of IL-18-mediated MCP-1/CCL2 production by PKC $\alpha$ and JNK-2 antisense ODNs. RA ST fibroblasts transfected with antisense ODNs directed against $\mathrm{PKC} \alpha$ or JNK-2 produced significantly less MCP-1/CCL2 compared with sense ODN-transfected cells, when stimulated with IL-18. This was consistent with the inhibition of MCP-1/CCL2 by SP600125 (a JNK inhibitor) and $\mathrm{RO}-318425$ (a $\mathrm{PKC} \alpha_{\mathrm{I}} / \beta_{\mathrm{II}}$ inhibitor) as described above. Transfection of RA ST fibroblasts with PKC $\delta$ antisense and sense ODNs did not affect IL-18induced MCP-1/CCL2 up-regulation (Figure 2C). Hence, while induction of SDF- $1 \alpha /$ CXCL12 by IL-18 involved $\mathrm{PKC} \delta$ and not $\mathrm{PKC} \alpha$, the converse was true for IL-18-induced MCP-1/CCL2 production.

IL-18-induced VEGF secretion in RA ST fibroblasts. Stimulation of RA ST fibroblasts with IL-18 significantly $(P<0.05)$ increased the release of VEGF compared with that observed in cells not treated with IL-18 (Figure 3A). This enhancement was more than 2-fold and was similar to that of MCP-1/CCL2.

Role of JNK and NF $\kappa B$ in VEGF production by IL-18 in fibroblasts. IL-18-induced VEGF production was significantly $(P<0.05)$ reduced by the JNK-1/2 inhibitor SP600125 and the $\mathrm{NF} \kappa \mathrm{B}$ inhibitor PDTC, suggesting that $\mathrm{JNK}$ and $\mathrm{NF} \kappa \mathrm{B}$ are essential in the production of VEGF by IL-18 (Figure 3B). However, 
A
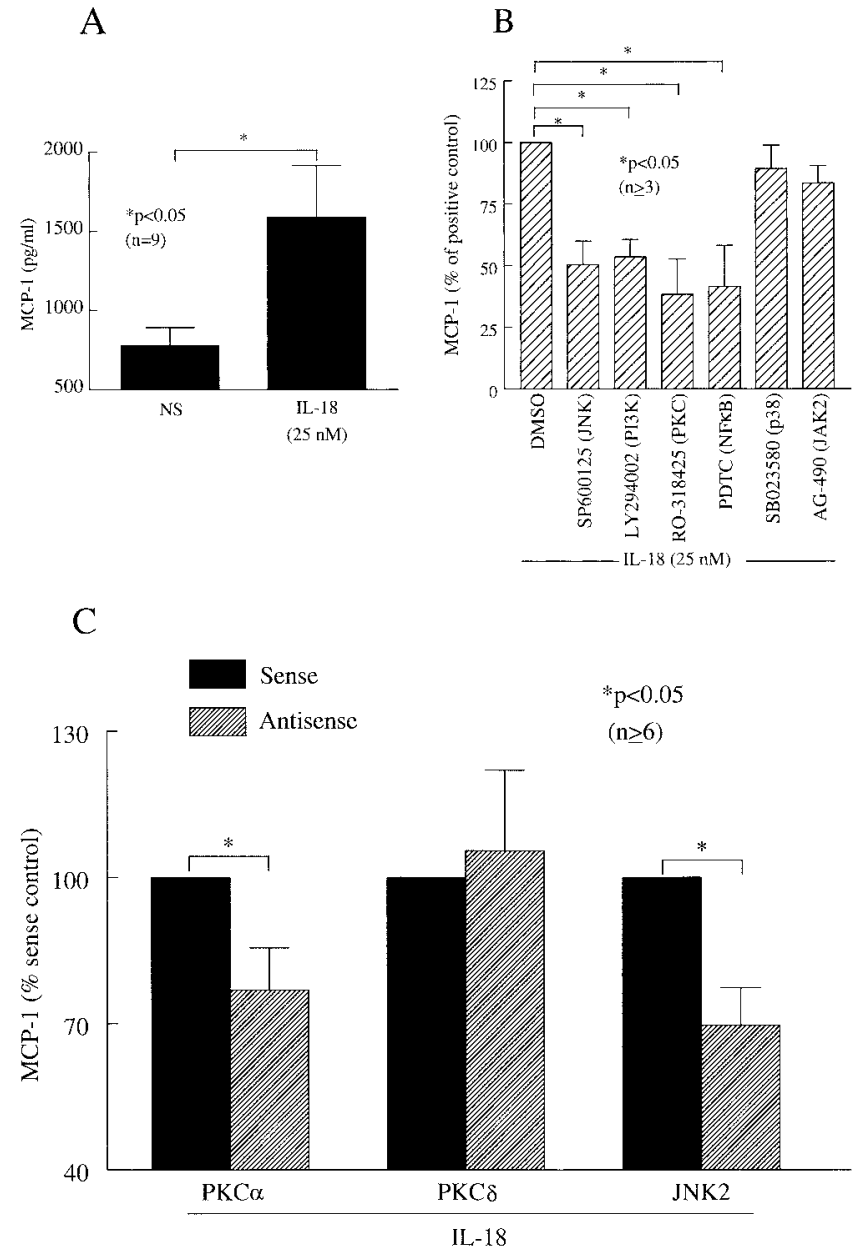

Figure 2. A, Stimulation of monocyte chemoattractant protein 1 (MCP-1)/CCL2 production in RA ST fibroblasts by IL-18. Cells were stimulated for 24 hours with IL-18 $(25 \mathrm{nM})$. Conditioned medium was collected, and the quantity of MCP-1/CCL2 released was determined by enzyme-linked immunosorbent assay. B, Reduction of IL-18mediated MCP-1/CCL2 production by treatment with inhibitors of JNK, PI3K, PKC, and NF $\kappa$ B. RA ST fibroblasts were treated with signaling inhibitors or DMSO (positive control) for 1 hour before 24-hour stimulation with $25 \mathrm{n} M$ IL-18. C, Significant inhibition of IL-18-induced MCP-1/CCL2 enhancement in RA ST fibroblasts by transfection with PKC $\alpha$ and JNK-2 antisense ODNs compared with PKC $\alpha$ and JNK-2 sense ODNs. Values are the mean and SEM. See Figure 1 for other definitions.

inhibitors of ERK-1/2 and p38 MAPK did not inhibit VEGF secretion by IL-18. Hence, while IL-18-induced production of SDF- $1 \alpha /$ CXCL12 may occur via p38 MAPK, production of VEGF does not.

Inhibition of IL-18-mediated VEGF upregulation by JNK-2 and NFKB antisense ODNs. We found that RA ST fibroblasts transfected with JNK-2 or $\mathrm{NF} \kappa \mathrm{B}$ antisense ODNs produced significantly less

VEGF compared with cells transfected with JNK-2 or $\mathrm{NF} \kappa \mathrm{B}$ sense ODNs or with $\mathrm{PKC} \beta$ or JNK-1 antisense ODNs, when stimulated with IL-18 (Figure 3C). These results indicate that IL-18 induction of VEGF production by RA ST fibroblasts occurred via JNK-2 or NF $\kappa$ B, but not via JNK-1.

Concentration- and time-dependence of IL-18 induction of SDF-1 $\alpha /$ CXCL12, MCP-1/CCL2, and VEGF secretion from RA ST fibroblasts. SDF- $1 \alpha /$ CXCL12 production was induced in RA ST fibroblasts

A
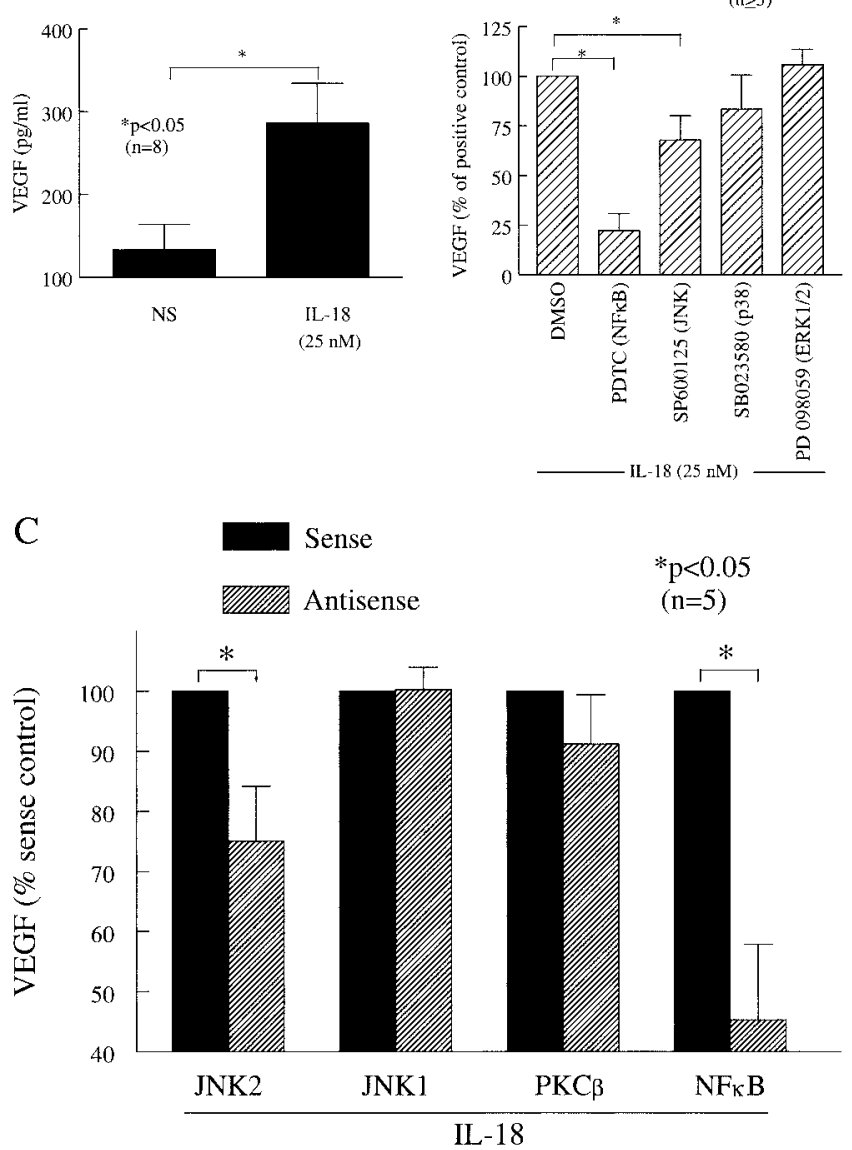

Figure 3. A, Stimulation of vascular endothelial growth factor (VEGF) production in RA ST fibroblasts by IL-18. Cells were stimulated for 24 hours with IL-18 $(25 \mathrm{nM})$. Conditioned medium was collected, and the quantity of VEGF released was determined by enzyme-linked immunosorbent assay. B, Reduction of IL-18-mediated VEGF production by treatment with inhibitors of $\mathrm{NF}_{\kappa} \mathrm{B}$ and JNK. RA ST fibroblasts were treated with signaling inhibitors or DMSO (positive control) for 1 hour before 24-hour stimulation with $25 \mathrm{n} M$ IL-18. C, Significant inhibition of IL-18-induced VEGF enhancement in RA ST fibroblasts by transfection with JNK-2 and NF $\kappa \mathrm{B}$ antisense ODNs compared with JNK-2 and NF $\kappa$ B sense ODNs. Values are the mean and SEM. See Figure 1 for other definitions. 

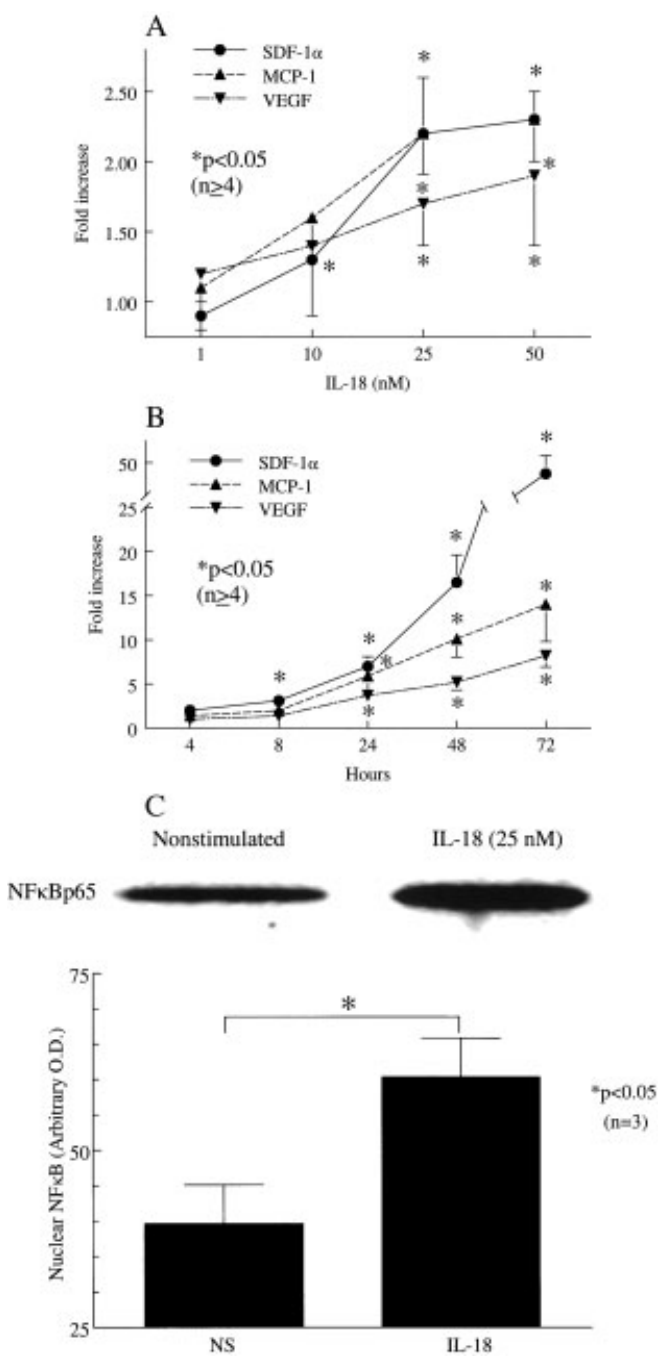

Figure 4. A, Concentration-dependence of SDF- $1 \alpha /$ CXCL12, monocyte chemoattractant protein 1 (MCP-1)/CCL2, and vascular endothelial growth factor (VEGF) production by IL-18. RA ST fibroblasts were stimulated for 24 hours with IL-18 at various concentrations. IL-18-induced SDF-1 $\alpha /$ CXCL12 up-regulation in RA ST fibroblasts started when IL-18 was administered at $10 \mathrm{n} M$ and peaked at $25-50$ $\mathrm{n} M$. IL-18 significantly increased RA ST fibroblast MCP-1/CCL2 secretion at $25 \mathrm{n} M$; this increase was $>2$-fold. IL-18-mediated VEGF production became significant with $25 \mathrm{n} M$ of IL-18. Values are the mean and SEM. B, Time-dependence of SDF- $1 \alpha /$ CXCL12, MCP-1/ CCL2, and VEGF production by IL-18. RA ST fibroblasts were stimulated with IL-18 $(25 \mathrm{n} M)$ for various lengths of time. IL-18 up-regulated SDF- $1 \alpha /$ CXCL12 starting at 8 hours, with maximum secretion at 72 hours. IL-18-induced RA ST fibroblast MCP-1/CCL2 production became significant at 24 hours. IL-18-mediated VEGF secretion was significant at 24 hours. Values are the mean and SEM. C, RA ST fibroblasts were stimulated with IL-18 (25 nM) for 30 minutes, and the nuclear fraction of lysates was probed for $\mathrm{p} 65 \mathrm{NF} \kappa \mathrm{B}$. There was a significant increase in nuclear localization of p $65 \mathrm{NF} \kappa \mathrm{B}$ in IL-18-stimulated fibroblasts compared with unstimulated fibroblasts. Optical density (OD) values are the mean and SEM. See Figure 1 for other definitions. with IL-18 starting at a concentration of $10 \mathrm{n} M$, with a maximum increase at IL-18 concentrations of 25-50 nM (Figure 4A). IL-18 at $1 \mathrm{n} M$ did not induce any increase in SDF- $1 \alpha /$ CXCL12 secretion. The increase in MCP-1/ CCL2 and VEGF production by RA ST fibroblasts induced by IL-18 became significant with the addition of IL-18 at $25 \mathrm{n} M$, in contrast to the increase in IL-18induced-SDF- $1 \alpha /$ CXCL12 secretion, which was significant with $10 \mathrm{n} M$ IL-18.

IL-18 treatment induced a significant increase in SDF- $1 \alpha /$ CXCL12 secretion beginning at 8 hours. IL-18induced MCP-1/CCL2 and -VEGF production in RA ST fibroblasts became significant at 24 hours. The maximum increase in all angiogenic factors occurred with 48-72 hours of IL-18 treatment (Figure 4B).

Significant increase in p65 NF $6 \mathrm{~B}$ nuclear localization in RA ST fibroblasts after IL-18 treatment. After RA ST fibroblasts were stimulated with IL-18, Western blotting was performed with the nuclear fraction, with probing for p $65 \mathrm{NF} \kappa \mathrm{B}$. Band densitometry analysis was performed with UN-Scan-It software (Silk Scientific, Orem, UT). We found that IL-18-induced nuclear localization of p65 NF $\kappa \mathrm{B}$ was significantly increased compared with that in unstimulated RA ST fibroblasts (Figure 4C).

IL-18 activation of p38 MAPK, JNK, ATF-2, and PKC $\delta$ phosphorylation. IL-18 induces phosphorylation of p38 MAPK, JNK-2, ATF-2, and PKC $\delta$ in RA ST fibroblasts in a time-dependent manner, with maximal response at 5-15 minutes. Phosphorylation of p38 MAPK increased at 5 minutes, with a maximum response at 15 minutes and a decrease to unstimulated levels at 30 minutes (Figure 5A). JNK phosphorylation increased strongly at 15 minutes and the increased level persisted through 45 minutes (Figure 5C). ATF-2 is a ubiquitously expressed member of the ATF/cAMP response element-binding family. ATF-2 is downstream of JNK signaling pathways induced by proinflammatory cytokines such as TNF $\alpha$ in RA ST fibroblasts (33). TNF $\alpha$-induced ATF-2 phosphorylation has been shown to be decreased in JNK-1/2-deficient murine embryo fibroblasts, suggesting that JNK and ATF-2 form a homodimer (34). In RA ST fibroblasts, IL-18 induced ATF-2 phosphorylation, which was increased at 15-30 minutes and decreased by 45 minutes (Figure 5E). IL-18-induced $\mathrm{PKC} \delta$ phosphorylation in RA ST fibroblasts was maximum at 15 minutes (Figure 5G). Reprobing of the blots with $\beta$-actin antibody demonstrated equal loading among the lanes (Figures $5 \mathrm{~B}, \mathrm{D}, \mathrm{F}$, and $\mathrm{H})$. 

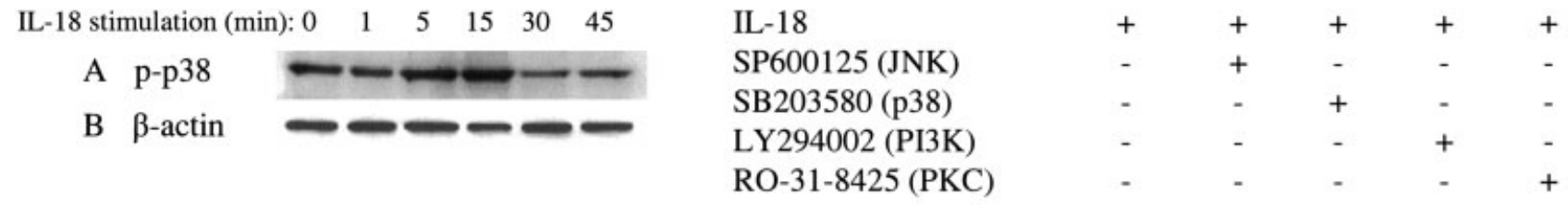

IL-18 stimulation (min): $0 \quad 1 \quad 5 \quad 15 \quad 30 \quad 45$

C p-JNK

D $\beta$-actin

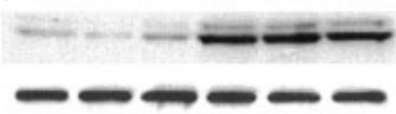

IL-18 stimulation (min): $0 \quad 1 \quad 5 \quad 15 \quad 30 \quad 45$

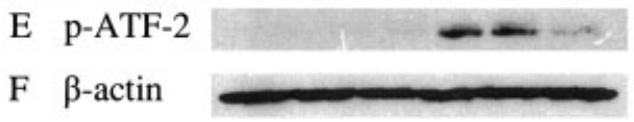

IL-18 stimulation (min): $\begin{array}{llllll}0 & 1 & 5 & 15 & 30 & 45\end{array}$

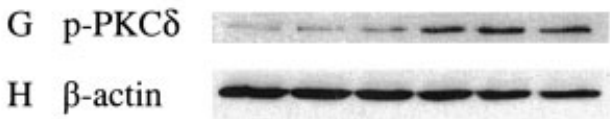

I $\mathrm{p}-\mathrm{JNK}$

J $\beta$-actin

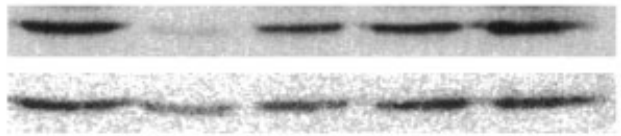

K p-ATF-2

L $\beta$-actin

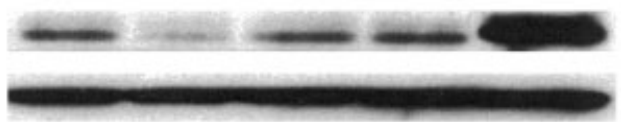

M $\mathrm{p}-\mathrm{NF} \kappa \mathrm{B}$

N $\beta$-actin

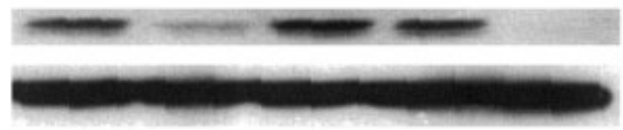

O $\mathrm{p}-\mathrm{PKC} \delta$

P $\quad$-actin

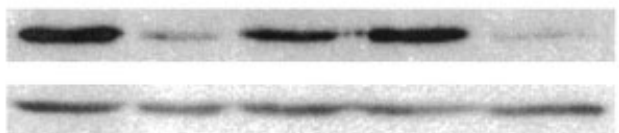

Figure 5. A-H, Time-dependence of IL-18 stimulation of phosphorylation of signaling intermediates. RA ST fibroblasts were stimulated with IL-18 $(25 \mathrm{n} M)$ for the indicated periods of time, medium was removed, and the cells were lysed. Equal amounts of protein were subjected to sodium dodecyl sulfate-polyacrylamide gel electrophoresis (SDS-PAGE), and Western blotting was performed with antibodies against the phosphorylated forms. IL-18-stimulated phosphorylation of p38 MAPK (A), JNK-2 (C), activating transcription factor 2 (ATF-2) (E), and PKC $\delta$ (G) is shown. To verify equal loading, the blot membranes were stripped and reprobed with $\beta$-actin $(\mathbf{B}, \mathbf{D}, \mathbf{F}$, and $\mathbf{H})$. Results are representative of 3 experiments. I-P, Evidence of activation of multiple pathways of IL-18 phosphorylation of signaling intermediates. RA ST fibroblasts were treated with signaling inhibitors or vehicle control (DMSO) for 1 hour before stimulation with IL-18 (25 nM) for 15 minutes. Medium was removed, and the cells were lysed. Equal amounts of protein were subjected to SDS-PAGE, and Western blotting was performed with antibodies against the phosphorylated forms. Phosphorylation of JNK-2 was affected only by the JNK inhibitor, and not by inhibitors of p38 MAPK, PI3K, or PKC (I). Phosphorylation of ATF-2 was inhibited only by the JNK inhibitor $(\mathbf{K})$. Phosphorylation of NF $\kappa$ B was inhibited by inhibitors of JNK and PKC (M). Phosphorylation of PKC $\delta$ was inhibited by inhibitors of JNK and PKC $(\mathbf{O})$. Blot membranes were stripped and reprobed with $\beta$-actin $(\mathbf{J}, \mathbf{L}, \mathbf{N}$, and $\mathbf{O})$. Results are representative of 3 or more experiments. See Figure 1 for other definitions.

Absence of crosstalk between IL-18-mediated signaling pathways. Western blotting was performed to determine which of the phosphorylated kinases might be upstream or downstream of the others. JNK phosphorylation was unaffected by inhibitors of p38 MAPK, PI3K, or PKC (Figure 5I), indicating that these molecules were not upstream in the JNK pathway. The phosphorylation of $\mathrm{PKC} \delta, \mathrm{NF}_{\kappa} \mathrm{B}$, and $\mathrm{ATF}-2$ was reduced by the JNK inhibitor but not by inhibitors of p38 MAPK, PI3K, or PKC (Figures 5K, M, and O), demonstrating that $\mathrm{PKC} \delta, \mathrm{NF} \kappa \mathrm{B}$, and $\mathrm{ATF}-2$ are downstream of JNK. NF $\kappa$ B phosphorylation was decreased by the JNK and PKC inhibitors, suggesting that both pathways converge at $\mathrm{NF} \kappa \mathrm{B}$.

Summary of signaling cascade of kinases mediating the action of IL-18 in RA ST fibroblasts. Based on the Western blotting results showing the effect of kinase inhibitors on phosphorylation, we deduced the signaling cascades of these kinases in relation to IL-18. These signaling cascades are depicted in Figure 6.

\section{DISCUSSION}

Angiogenesis is a critical feature in the development of vasculoproliferative diseases such as RA $(15,35,36)$. IL-18 is a pleiotropic cytokine that has roles in innate and adaptive immune responses and in Th1and Th2-related autoimmune diseases (1). Our group has previously shown that IL-18 is an angiogenic factor and up-regulates vascular cell adhesion molecule 1 (VCAM-1) as well as CXC chemokines such as IL-8/ CXCL8, GRO $\alpha /$ CXCL1, and ENA-78/CXCL5 in RA ST fibroblasts $(25,26,37)$. Angiogenesis and cell adhesion contribute to leukocyte ingress into inflamed RA 

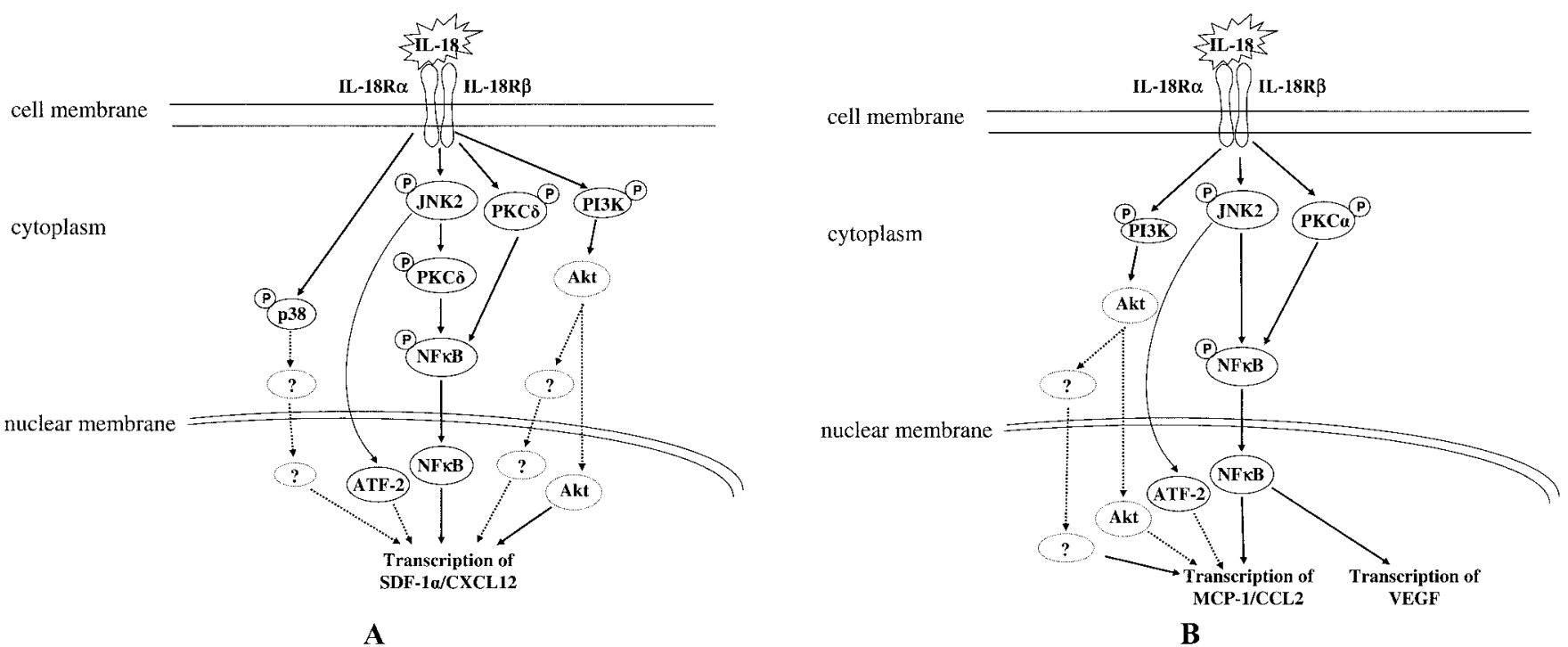

Figure 6. Signaling pathways of kinase-mediated up-regulation of A, SDF- $1 \alpha /$ CXCL12 and B, monocyte chemoattractant protein 1 (MCP-1)/CCL2 and vascular endothelial growth factor (VEGF) by IL-18 in RA ST fibroblasts. Four different signaling pathways, p38 MAPK, JNK-2, PKC $\delta$, and PI3K, mediate the up-regulation of SDF- $1 \alpha / \mathrm{CXCL} 12$. NF $\kappa \mathrm{B}$ and activating transcription factor 2 (ATF-2) are the downstream target of JNK-2, and PKC is upstream of NF $\kappa$ B. MCP-1/CCL2 is up-regulated by IL-18 via PI3K, JNK-2, PKC, and NF $\kappa$ B pathways. IL-18 increases the up-regulation of VEGF via JNK-2 and NF $\kappa$ B, while p38 MAPK is not involved. Dotted arrows and circles represent hypothesized pathways. IL-18R $\alpha=$ IL-18 receptor $\alpha$ (see Figure 1 for other definitions).

ST. IL-18 is a very critical cytokine to target in RA because of its ability to induce chemokine release, adhesion molecule expression, and angiogenesis.

Pablos et al showed that TNF $\alpha$, transforming growth factor $\beta$, VEGF, and hypoxia did not induce SDF- $1 \alpha /$ CXCL12 messenger RNA (mRNA) in RA ST fibroblasts, but they did detect SDF- $1 \alpha /$ CXCL12 on fibroblasts lining the synovium and endothelium in RA, suggesting that SDF- $1 \alpha /$ CXCL12 is not inducible by the cytokines they examined (13). Nanki and colleagues demonstrated that CD40 ligation induces increased expression of SDF- $1 \alpha /$ CXCL12 in RA ST fibroblasts (9). Conversely, Hitchon et al reported that hypoxiainducible factor $1 \alpha$ (HIF- $1 \alpha)$ and VEGF enhanced expression of SDF- $1 \alpha /$ CXCL12 mRNA in RA ST fibroblasts, although they did not demonstrate induction of SDF- $1 \alpha /$ CXCL1 2 protein by TNF $\alpha$ or IL- $1 \beta$ in RA ST fibroblasts (38). Burger et al reported the constitutive expression of SDF- $1 \alpha /$ CXCL12 mRNA in human RA and OA ST fibroblasts (39). We also observed the production of SDF- $1 \alpha /$ CXCL12 in unstimulated RA ST fibroblasts; however, its production was increased significantly with IL-18 stimulation. Hence, IL-18, HIF- $1 \alpha$, and VEGF induce SDF- $1 \alpha /$ CXCL12 production in RA ST fibroblasts.

The signaling mechanisms involved in IL-18- induced up-regulation of SDF- $1 \alpha /$ CXCL12 in RA ST fibroblasts have not been examined previously. In the current study, we found that IL-18-induced SDF- $1 \alpha /$ CXCL12 secretion in RA ST fibroblasts is dependent on JNK, PI3K, p38 MAPK, PKC $\delta$, and $\mathrm{NF} \kappa \mathrm{B}$; chemical inhibitors of these signaling intermediates inhibited SDF- $1 \alpha /$ CXCL12 production. However, JAK- 2 and ERK-1/2 inhibitors did not inhibit IL-18-induced SDF$1 \alpha /$ CXCL12 production. We confirmed our results using sense and antisense ODNs directed against signaling intermediates. PKC $\delta$ antisense ODNs and a dominantnegative mutant of p38 MAPK significantly reduced IL-18-induced SDF- $1 \alpha /$ CXCL12 production in RA ST fibroblasts. IL-18 induction of SDF- $1 \alpha /$ CXCL12 was found to be concentration- and time-dependent, with a significant increase at an IL-18 concentration of $10 \mathrm{n} M$. Production of SDF- $1 \alpha /$ CXCL12 in RA ST fibroblasts was further increased with 25-50 $\mathrm{n} M$ IL-18.

IL-18 increases the production of some proinflammatory mediators, such as $\mathrm{TNF} \alpha$, IL- $1 \beta$, nitric oxide, IL-8/CXCL8, ENA-78/CXCL5, and GRO $\alpha /$ CXCL1, in monocytes and fibroblasts $(2,3,25)$, and we therefore examined whether IL-18 up-regulates MCP-1/ CCL2 in RA fibroblasts. The level of MCP-1/CCL2 in RA ST fibroblasts doubled with 24-hour IL-18 treatment. IL-18 induces the activation of signaling mole- 
cules that are involved in the production of proinflammatory cytokines in RA ST fibroblasts and leukocytes $(2,3,25,40)$. Recently, Yoo et al $(40)$ reported that IL-18 induces MCP-1/CCL2 production by PI3K and ERK-1/2 in mouse peritoneal macrophages. In the present study, IL-18-induced production of MCP-1/CCL2 in RA ST fibroblasts was mediated by JNK, PI3K, PKC, and $\mathrm{NF} \kappa \mathrm{B} . \mathrm{PKC} \alpha$ and JNK-2 antisense ODNs significantly inhibited IL-18-induced production of MCP-1/CCL2 compared with $\mathrm{PKC} \alpha$ or JNK-2 sense ODNs, while PKC $\delta$ antisense ODN did not. This is in sharp contrast to the IL-18-induced production of SDF- $1 \alpha /$ CXCL12, which occurred via $\mathrm{PKC} \delta$. Also, unlike IL-18-induced production of SDF- $1 \alpha /$ CXCL12, which proceeded via p38 MAPK, production of MCP-1/CCL2 did not involve p38 MAPK.

Hence, the data suggest that different isoforms of PKC can be activated by IL-18 in RA ST fibroblasts, leading to the secretion of different chemokines, and that production of different chemokines by RA ST fibroblasts may utilize signaling molecules differentially, as is the case with p38 MAPK. IL-18 increased RA ST fibroblast secretion of MCP-1/CCL2 at $25 \mathrm{n} M$, in contrast to SDF-1 $\alpha /$ CXCL12 production, which was significantly increased with IL-18 at $10 \mathrm{nM}$. Similarly, IL-18 induced significant SDF- $1 \alpha /$ CXCL12 secretion in RA ST fibroblasts at 8 hours, compared with MCP-1/CCL2 up-regulation, which became significant at 24 hours. These results indicate that IL-18 mediates production of different angiogenic factors in a concentration- and time-dependent manner.

Angiogenesis is important in pannus growth and proliferation. Increased angiogenesis causes additional leukocyte recruitment and provides nutrients and oxygen to the growing pannus. Various cytokines, such as $\mathrm{TNF} \alpha$, IL-8, basic fibroblast growth factor, VEGF, and hepatocyte growth factor, contribute to the angiogenic process $(35,36)$. Administration of soluble VEGF receptor 1 attenuates arthritis in murine CIA (24). IL-18 enhances the production of VEGF in RA ST fibroblasts. Our results are consistent with those of a recent study by Cho et al, who found that IL-18 increases the production of VEGF in RA ST fibroblasts (41). Our findings indicate that IL-18 induces VEGF secretion via JNK and $\mathrm{NF} \kappa \mathrm{B}$, since inhibitors of JNK-1/2 and NF $\kappa \mathrm{B}$ significantly reduced VEGF production. We confirmed our data using sense and antisense ODNs. Cho and colleagues identified a role of activator protein 1 (AP-1), but did not demonstrate a role of $\mathrm{NF} \kappa \mathrm{B}$, in IL-18induced production of VEGF in RA ST fibroblasts (41). The reason for the discrepant results between our study and theirs in this regard is not clear. Our group has previously shown that IL-18 enhances RA ST fibroblast VCAM-1 expression via AP-1 and NF $\kappa$ B signaling pathways (26). Hence, it is likely that IL-18 induces production of VEGF in RA ST fibroblasts via either $\mathrm{NF} \kappa \mathrm{B}$ or AP-1.

IL-18 activates phosphorylation of JNK, p38 MAPK, $\mathrm{PKC} \delta$, and ATF-2 in RA ST fibroblasts in a time-dependent manner, starting at 5 minutes and with a maximum response between 15 and 30 minutes, which subsides by 45 minutes. Our group has previously shown that IL-18 induces phosphorylation of Src, PI3K, Akt, Raf, ERK-1/2, AP-1, and NF $\kappa$ B in RA ST fibroblasts (26). The present report is the first to describe activation of PKC $\delta$ and ATF-2 by IL-18 in RA ST fibroblasts. Kanakaraj et al and Kalina et al found that IL-18 induces JNK and p38 MAPK activation in natural killer and T helper cell lines $(42,43)$, in accordance with our findings in RA ST fibroblasts. In contrast to those reports, Yoo and colleagues did not observe activation of JNK and p38 MAPK in mouse macrophages (40), reaffirming that IL-18-induced activation of these signaling pathways may depend on cell type.

$\mathrm{NF} \kappa \mathrm{B}$ is an inducible transcription factor that is responsible for regulating the expression of genes involved in inflammation $(25,44)$. In this study, we showed that IL-18-induced up-regulation of SDF- $1 \alpha /$ CXCL12, $\mathrm{MCP}-1 / \mathrm{CCL} 2$, and VEGF was mediated via $\mathrm{NF} \kappa \mathrm{B}$. It has previously been shown that most of the signaling pathways activated by IL-18 converge on NF $\kappa \mathrm{B}(26,45)$, indicating that $\mathrm{NF} \kappa \mathrm{B}$ is critical in IL-18-induced secretion of proinflammatory cytokines in chronic inflammatory diseases such RA. We found a significant increase of p65 NF $\kappa \mathrm{B}$ nuclear localization in RA ST fibroblasts stimulated for 30 minutes with IL-18, compared with unstimulated cells (Figure 4C). In contrast to these results, some studies using mouse macrophages and epithelial cells did not demonstrate activation of $\mathrm{NF} \kappa \mathrm{B}$ by IL-18 $(40,46)$, again suggesting that such activation depends on the immune environment and cell type examined.

With regard to IL-18 signaling in RA ST fibroblasts, we found that JNK is upstream of ATF-2, NF $\kappa$ B, and $\mathrm{PKC}$, since the activation of $\mathrm{ATF}-2, \mathrm{NF} \kappa \mathrm{B}$, and PKC was reduced by a JNK inhibitor. Members of the MAPK family, including JNK, ERK-1/2, and p38 MAPK, have been implicated in the pathogenesis of RA (47). JNK activation enhances joint destruction and expression of MMPs by RA ST fibroblasts (48). A selective JNK inhibitor, SP600125, has been shown to provide striking protection against bone and cartilage 
destruction in rat adjuvant-induced arthritis (48). PI3K blockade suppresses joint inflammation as well as bone and cartilage damage in a murine CIA model (49), suggesting that PI3K has an important role in RA.

$\mathrm{PKC}$ is composed of a family of phospholipiddependent serine/threonine kinases, which have 11 isoenzymes that participate in many cellular functions including proliferation, differentiation, apoptosis, and angiogenesis (27,50). Activation of $\mathrm{PKC} \beta$ mediates VEGF-dependent tumor growth and angiogenesis (27). $\mathrm{PKC} \delta$ and $\mathrm{PI} 3 \mathrm{~K}$ have important roles in $\mathrm{TNF} \alpha-$ mediated $\mathrm{NF}_{\kappa} \mathrm{B}$ activation in human neutrophils (51). PKC $\delta$ activation by IL-18 suggests that it exerts proinflammatory action in RA by phosphorylating NF $\kappa$ B. JNK-2 enhances the production of angiogenic factors and MMP in RA ST fibroblasts, and inhibition of JNK-2/ATF-2 protects against cartilage and bone erosion (48). These findings suggest that these signaling intermediates are important in RA, particularly in relation to cytokine-induced joint destruction.

In terms of IL-18 signaling in RA ST fibroblasts, we did not identify crosstalk between PI3K, JNK, and p38 MAPK; inhibitors of PI3K and p38 MAPK did not decrease JNK-1/2 and ATF-2 phosphorylation. The finding that an inhibitor of JNK-1/2 reduced IL-18induced activation of $\mathrm{ATF}-2$ and $\mathrm{NF} \kappa \mathrm{B}$ in RA ST fibroblasts suggests that JNK-1/2 is upstream of ATF-2 and $\mathrm{NF} \kappa \mathrm{B}$.

In conclusion, the present results show that IL-18 increases the production of SDF- $1 \alpha /$ CXCL12, MCP-1/ CCL2, and VEGF via overlapping but sometimes different signaling intermediates. Targeting of IL-18 or its signaling pathways is a potentially novel therapeutic strategy for diseases such as RA.

\section{ACKNOWLEDGMENT}

We are grateful to Dr. Pawan Kumar for providing the dominant-negative mutants of p38 MAPK.

\section{AUTHOR CONTRIBUTIONS}

Dr. Amin had full access to all of the data in the study and takes responsibility for the integrity of the data and the accuracy of the data analysis.

Study design. Amin, Koch.

Acquisition of data. Amin, Mansfield, Pakozdi, Campbell, Ahmed, Martinez.

Analysis and interpretation of data. Amin, Mansfield, Pakozdi, Campbell, Ahmed, Martinez, Koch.

Manuscript preparation. Amin, Mansfield, Koch.

Statistical analysis. Mansfield, Pakozdi, Koch.

\section{REFERENCES}

1. Okamura H, Tsutsi H, Komatsu T, Yutsudo M, Hakura A, Tanimoto T, et al. Cloning of a new cytokine that induces IFN- $\gamma$ production by T cells. Nature 1995;378:88-91.

2. Dinarello CA. IL-18: a Th1-inducing, proinflammatory cytokine and new member of the IL-1 family. J Allergy Clin Immunol 1999;103:11-24.

3. Dai SM, Matsuno $\mathrm{H}$, Nakamura $\mathrm{H}$, Nishioka $\mathrm{K}$, Yudoh $\mathrm{K}$. Interleukin-18 enhances monocyte tumor necrosis factor $\alpha$ and interleukin- $1 \beta$ production induced by direct contact with $\mathrm{T}$ lymphocytes: implications in rheumatoid arthritis. Arthritis Rheum 2004;50:432-43.

4. Gracie JA, Forsey RJ, Chan WL, Gilmour A, Leung BP, Greer $\mathrm{MR}$, et al. A proinflammatory role for IL-18 in rheumatoid arthritis. J Clin Invest 1999;104:1393-401.

5. Joosten LA, van de Loo FA, Lubberts E, Helsen MM, Netea MG, van der Meer JW, et al. An IFN- $\gamma$-independent proinflammatory role of IL-18 in murine streptococcal cell wall arthritis. J Immunol 2000;165:6553-8.

6. Smeets RL, van de Loo FA, Arntz OJ, Bennink MB, Joosten LA, van den Berg WB. Adenoviral delivery of IL-18 binding protein C ameliorates collagen-induced arthritis in mice. Gene Ther 2003; 10:1004-11.

7. Bleul CC, Fuhlbrigge RC, Casasnovas JM, Aiuti A, Springer TA. A highly efficacious lymphocyte chemoattractant, stromal cellderived factor 1 (SDF-1). J Exp Med 1996;184:1101-9.

8. Kanbe K, Takagishi K, Chen Q. Stimulation of matrix metalloprotease 3 release from human chondrocytes by the interaction of stromal cell-derived factor 1 and CXC chemokine receptor 4 . Arthritis Rheum 2002;46:130-7.

9. Nanki T, Hayashida K, El-Gabalawy HS, Suson S, Shi K, Girschick $\mathrm{HJ}$, et al. Stromal cell-derived factor-1-CXC chemokine receptor 4 interactions play a central role in $\mathrm{CD}^{+} \mathrm{T}$ cell accumulation in rheumatoid arthritis synovium. J Immunol 2000;165:6590-8.

10. Blades MC, Ingegnoli F, Wheller SK, Manzo A, Wahid S, Panayi GS, et al. Stromal cell-derived factor 1 (CXCL12) induces monocyte migration into human synovium transplanted onto SCID mice. Arthritis Rheum 2002;46:824-36.

11. Matthys P, Hatse S, Vermeire K, Wuyts A, Bridger G, Henson GW, et al. AMD3100, a potent and specific antagonist of the stromal cell-derived factor-1 chemokine receptor CXCR4, inhibits autoimmune joint inflammation in IFN- $\gamma$ receptor-deficient mice. J Immunol 2001;167:4686-92.

12. Salcedo R, Wasserman K, Young HA, Grimm MC, Howard OM, Anver MR, et al. Vascular endothelial growth factor and basic fibroblast growth factor induce expression of CXCR4 on human endothelial cells: in vivo neovascularization induced by stromalderived factor-1 $\alpha$. Am J Pathol 1999;154:1125-35.

13. Pablos JL, Santiago B, Galindo M, Torres C, Brehmer MT, Blanco FJ, et al. Synoviocyte-derived CXCL12 is displayed on endothelium and induces angiogenesis in rheumatoid arthritis. J Immunol 2003;170:2147-52.

14. Tachibana K, Hirota S, Lizasa H, Yoshida H, Kawabata K, Kataoka Y, et al. The chemokine receptor CXCR4 is essential for vascularization of the gastrointestinal tract. Nature 1998;393: $591-4$.

15. Koch AE, Kunkel SL, Harlow LA, Johnson B, Evanoff HL, Haines GK, et al. Enhanced production of monocyte chemoattractant protein-1 in rheumatoid arthritis. J Clin Invest 1992;90:772-9.

16. Feldmann M, Brennan FM, Maini RN. Role of cytokines in rheumatoid arthritis. Annu Rev Immunol 1996;14:397-440.

17. Lu B, Rutledge BJ, Gu L, Fiorillo J, Lukacs NW, Kunkel SL, et al. Abnormalities in monocyte recruitment and cytokine expression in monocyte chemoattractant protein 1-deficient mice. J Exp Med 1998;187:601-8.

18. Carr MW, Roth SJ, Luther E, Rose SS, Springer TA. Monocyte 
chemoattractant protein 1 acts as a T-lymphocyte chemoattractant. Proc Natl Acad Sci U S A 1994;91:3652-6.

19. Hong KH, Ryu J, Han KH. Monocyte chemoattractant protein-1induced angiogenesis is mediated by vascular endothelial growth factor-A. Blood 2005;105:1405-7.

20. Ogata H, Takeya M, Yoshimura T, Takagi K, Takahashi K. The role of monocyte chemoattractant protein-1 (MCP-1) in the pathogenesis of collagen-induced arthritis in rats. J Pathol 1997; 182:106-14.

21. Dvorak HF, Detmar M, Claffey KP, Nagy JA, van de Water L, Senger DR. Vascular permeability factor/vascular endothelial growth factor: an important mediator of angiogenesis in malignancy and inflammation. Int Arch Allergy Immunol 1995;107: 233-5.

22. Brown LF, Detmar M, Claffey K, Nagy JA, Feng D, Dvorak AM, et al. Vascular permeability factor/vascular endothelial growth factor: a multifunctional angiogenic cytokine. EXS 1997;79: 233-69.

23. Koch AE, Harlow LA, Haines GK, Amento EP, Unemori EN, Wong WL, et al. Vascular endothelial growth factor: a cytokine modulating endothelial function in rheumatoid arthritis. J Immunol 1994;152:4149-56.

24. Afuwape AO, Feldmann M, Paleolog EM. Adenoviral delivery of soluble VEGF receptor 1 (sFlt-1) abrogates disease activity in murine collagen-induced arthritis. Gene Ther 2003;10:1950-60.

25. Morel JC, Park CC, Kumar P, Koch AE. Interleukin-18 induces rheumatoid arthritis synovial fibroblast CXC chemokine production through $\mathrm{NF} \kappa \mathrm{B}$ activation. Lab Invest 2001;81:1371-83.

26. Morel JC, Park CC, Zhu K, Kumar P, Ruth JH, Koch AE. Signal transduction pathways involved in rheumatoid arthritis synovial fibroblast interleukin-18-induced vascular cell adhesion molecule-1 expression. J Biol Chem 2002;277:34679-91.

27. Yoshiji H, Kuriyama S, Ways DK, Yoshii J, Miyamoto Y, Kawata $\mathrm{M}$, et al. Protein kinase $\mathrm{C}$ lies on the signaling pathway for vascular endothelial growth factor-mediated tumor development and angiogenesis. Cancer Res 1999;59:4413-8.

28. Woods JM, Mogollon A, Amin MA, Martinez RJ, Koch AE. The role of COX-2 in angiogenesis and rheumatoid arthritis. Exp Mol Pathol 2003;74:282-90.

29. Ahmed S, Pakozdi A, Koch AE. Regulation of interleukin$1 \beta$-induced chemokine production and matrix metalloproteinase 2 activation by epigallocatechin-3-gallate in rheumatoid arthritis synovial fibroblasts. Arthritis Rheum 2006;54:2393-401.

30. Kumar P, Hosaka S, Koch AE. Soluble E-selectin induces monocyte chemotaxis through Src family tyrosine kinases. J Biol Chem 2001;276:21039-45.

31. Bokarewa M, Hultgren O. Is interleukin-18 useful for monitoring rheumatoid arthritis? Scand J Rheumatol 2005;34:433-6.

32. Amin MA, Haas CS, Zhu K, Mansfield PJ, Kim MJ, Lackowski NP, et al. Migration inhibitory factor up-regulates vascular cell adhesion molecule-1 and intercellular adhesion molecule-1 via Src, PI3 kinase, and NF $\kappa$ B. Blood 2006;107:2252-61.

33. Gerritsen ME, Shen CP, Perry CA. Synovial fibroblasts and the sphingomyelinase pathway: sphingomyelin turnover and ceramide generation are not signaling mechanisms for the actions of tumor necrosis factor- $\alpha$. Am J Pathol 1998;152:505-12.

34. Ventura JJ, Kennedy NJ, Lamb JA, Flavell RA, Davis RJ. c-Jun $\mathrm{NH}(2)$-terminal kinase is essential for the regulation of AP-1 by tumor necrosis factor. Mol Cell Biol 2003;23:2871-82.

35. Koch AE, Polverini PJ, Kunkel SL, Harlow LA, DiPietro LA, Elner VM, et al. Interleukin-8 as a macrophage-derived mediator of angiogenesis. Science 1992;258:1798-801.
36. Szekanecz Z, Gaspar L, Koch AE. Angiogenesis in rheumatoid arthritis. Front Biosci 2005;10:1739-53.

37. Park CC, Morel JC, Amin MA, Connors MA, Harlow LA, Koch AE. Evidence of IL-18 as a novel angiogenic mediator. J Immunol 2001;167:1644-53.

38. Hitchon C, Wong K, Ma G, Reed J, Lyttle D, El-Gabalawy H. Hypoxia-induced production of stromal cell-derived factor 1 (CXCL12) and vascular endothelial growth factor by synovial fibroblasts. Arthritis Rheum 2002;46:2587-97.

39. Burger JA, Zvaifler NJ, Tsukada N, Firestein GS, Kipps TJ. Fibroblast-like synoviocytes support B-cell pseudoemperipolesis via a stromal cell-derived factor-1- and CD106(VCAM-1)-dependent mechanism. J Clin Invest 2001;107:305-15.

40. Yoo JK, Kwon H, Khil LY, Zhang L, Jun HS, Yoon JW. IL-18 induces monocyte chemotactic protein-1 production in macrophages through the phosphatidylinositol 3-kinase/Akt and MEK/ ERK1/2 pathways. J Immunol 2005;175:8280-6.

41. Cho ML, Jung YO, Moon YM, Min SY, Yoon CH, Lee SH, et al. Interleukin-18 induces the production of vascular endothelial growth factor (VEGF) in rheumatoid arthritis synovial fibroblasts via AP-1-dependent pathways. Immunol Lett 2006;103:159-66.

42. Kanakaraj P, Ngo K, Wu Y, Angulo A, Ghazal P, Harris CA, et al. Defective interleukin (IL)-18-mediated natural killer and T helper cell type 1 responses in IL-1 receptor-associated kinase (IRAK)deficient mice. J Exp Med 1999;189:1129-38.

43. Kalina U, Kauschat D, Koyama N, Nuernberger H, Ballas K, Koschmieder S, et al. IL-18 activates STAT3 in the natural killer cell line 92, augments cytotoxic activity, and mediates IFN- $\gamma$ production by the stress kinase p38 and by the extracellular regulated kinases p44erk-1 and p42erk-21. J Immunol 2000;165: 1307-13.

44. Feldmann M, Andreakos E, Smith C, Bondeson J, Yoshimura S, Kiriakidis $\mathrm{S}$, et al. Is NF- $\kappa \mathrm{B}$ a useful therapeutic target in rheumatoid arthritis? Ann Rheum Dis 2002;61 Suppl 2:ii13-8.

45. Matsumoto S, Tsuji-Takayama K, Aizawa Y, Koide K, Takeuchi $\mathrm{M}$, Ohta $\mathrm{T}$, et al. Interleukin-18 activates NF- $\kappa \mathrm{B}$ in murine $\mathrm{T}$ helper type 1 cells. Biochem Biophys Res Commun 1997;234: 454-7.

46. Lee JK, Kim SH, Lewis EC, Azam T, Reznikov LL, Dinarello CA. Differences in signaling pathways by IL- $1 \beta$ and IL-18. Proc Natl Acad Sci U S A 2004;101:8815-20.

47. Schett G, Tohidast-Akrad M, Smolen JS, Schmid BJ, Steiner CW, Bitzan $\mathrm{P}$, et al. Activation, differential localization, and regulation of the stress-activated protein kinases, extracellular signalregulated kinase, c-JUN N-terminal kinase, and p38 mitogenactivated protein kinase, in synovial tissue and cells in rheumatoid arthritis. Arthritis Rheum 2000;43:2501-12.

48. Han Z, Boyle DL, Chang L, Bennett B, Karin M, Yang L, et al. c-Jun N-terminal kinase is required for metalloproteinase expression and joint destruction in inflammatory arthritis. J Clin Invest 2001;108:73-81.

49. Camps M, Ruckle T, Ji H, Ardissone V, Rintelen F, Shaw J, et al. Blockade of PI3K $\gamma$ suppresses joint inflammation and damage in mouse models of rheumatoid arthritis. Nat Med 2005;11:936-43.

50. Mellor H, Parker PJ. The extended protein kinase C superfamily. Biochem J 1998;332:281-92.

51. Kilpatrick LE, Sun S, Korchak HM. Selective regulation by $\delta$-PKC and PI 3-kinase in the assembly of the antiapoptotic TNFR-1 signaling complex in neutrophils. Am J Physiol Cell Physiol 2004;287:C633-42. 